\title{
URBAN MODELLING WITH TYPOLOGICAL APPROACH. CASE STUDY: MERIDA, YUCATAN, MEXICO.
}

\author{
A. Rodriguez ${ }^{\text {a }}$ \\ ${ }^{a}$ School of Architecture, Universidad Anahuac Mayab, Merida, Mexico - antonio.rodriguez@ anahuac.mx
}

KEY WORDS: Virtual Reconstruction, Typological modelling, Parametric modelling, Merida, Mexico, Colonial Era.

\begin{abstract}
:
In three-dimensional models of urban historical reconstruction, missed contextual architecture faces difficulties because it does not have much written references in contrast to the most important monuments. This is the case of Merida, Yucatan, Mexico during the Colonial Era (1542-1810), which has lost much of its heritage. An alternative to offer a hypothetical view of these elements is a typological - parametric definition that allows a 3D modeling approach to the most common features of this heritage evidence.
\end{abstract}

\section{INTRODUCTION}

Currently digital media can represent reliably and with a high degree of realism the historical conditions of buildings that do not exist today. These operations have received various names: "historical reconstruction", "virtual restoration" or even "visual recovery." Given the vastness and popularity of threedimensional digital media, these reconstructions are "trendy" and are widely available in broad media, primarily the Internet.

However, in many cases much of the historical three-dimensional models have parts which cannot depict its precise characteristics. Instead of showing their degree of hypotheses, the modelers present them as finished products, which do not necessarily correspond to the reality of the settlement and are scientifically incorrect. In 2012 we formulated a doctoral thesis in which enunciate a General Methodology for Virtual Historical Reconstruction (Rodriguez, 2012:61), and as one of its most important statements it gives way to the "uncertainty" or degree of partial knowledge of certain parts of urban virtual models.

This concern for the veracity of historical virtual reconstructions is attended in recent Conservation letters issued by UNESCO as the London Charter and the Charter of Seville (2009), which recommends demonstrating alternative solutions to the same reconstructive problem when there's not sufficient evidence, and always based on the same existing documentation.

Thus, to raise a virtual historical reconstruction of an urban site, there will always be considered as a component of first-order criteria to be taken how we should solve the "gaps" that present the layout of the virtual model in which built environments recreate the past.

\section{ARCHITECTURAL TYPOLOGY DURING COLONIAL ERA IN MERIDA}

International law on restoration as the Venice Charter (1964) imposes significant restrictions when proposing new elements to existing historic structures. However, one of the advantages of virtual historical reconstruction is to display, in a very realistic way and without jeopardy to the physical integrity of built heritage, possible alternatives for the missing parts that time or destructive actions have been deleted.

\footnotetext{
* Corresponding author
}

The typological approach is, therefore, a valuable tool to read, analyze, interpret and evaluate urban and architectural objects, which in a first instance is used to identify the elements that share a group of buildings and the coherence of its internal structure (Guerrero 1998:55). Its goal is to know the production process of an architectural or urban object and understand what has been derived and how it evolved, as well as its relationship with other similar cases, which is known as typological contrasting.

This was the starting point for the architecture of the city of Merida in the Colonial Era, because monumental landmarks are well documented as the Cathedral, the Montejo's House or public buildings, however the contextual buildings are less, particularly housing and that is where there's the greatest uncertainty.

The research project consisted of virtually rebuild the Main Square of Merida and its eight surrounding blocks during the Colonial Period (1542-1800 a.C.), using various information sources such as archives, libraries, maps, drawings, photographs, etc. as well as by direct observation of the monumental remains. Thus there were inferred possible construction stages on both notorious buildings and contextual less-hierarchy housing.

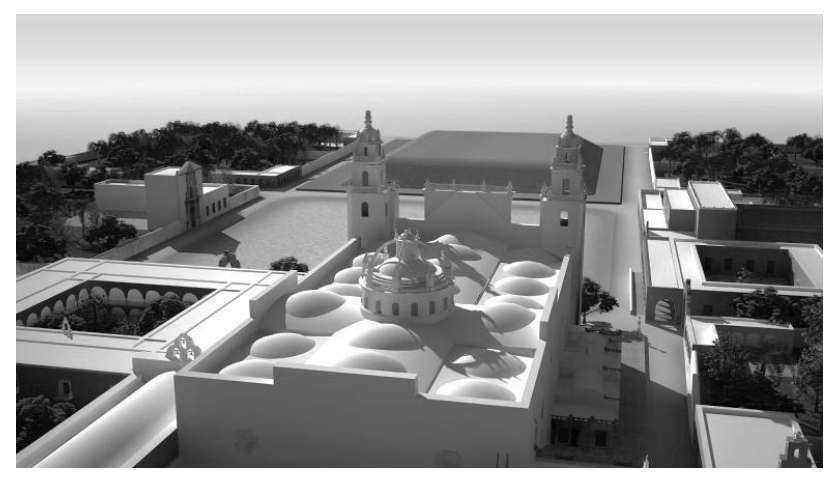

Figure 1. Main Square of Merida from the back side of Cathedral. Around the square are observed contextual houses, which were modeled parametrically.

Previous studies have shown (Pacheco 1998:35) that such housing typologically evolutionarily behaved as follows: The typical construction sequence on corner lot began in squad with corridors, which subsequently were closing in a "C" shape and ended up forming courtyards plants in one and two storey. 


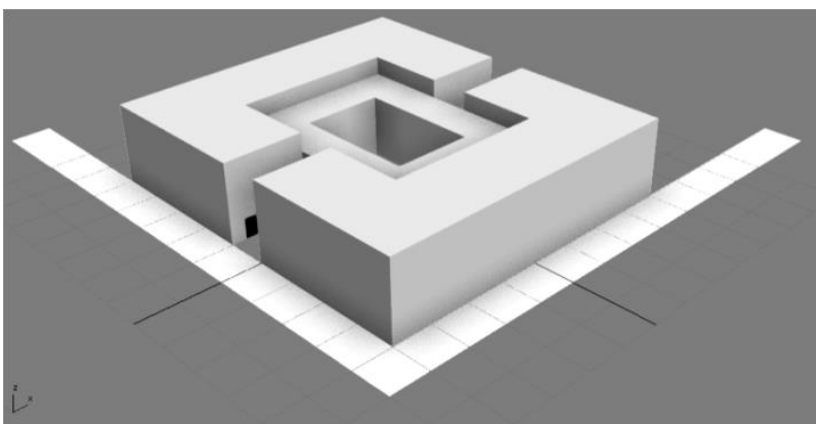

Figure 2. Colonial Merida housing at corner lot.

In middle lots, the house started with front and rear bay corridors, following the creation of sequenced patios. The interconnections between courtyards were very diverse.

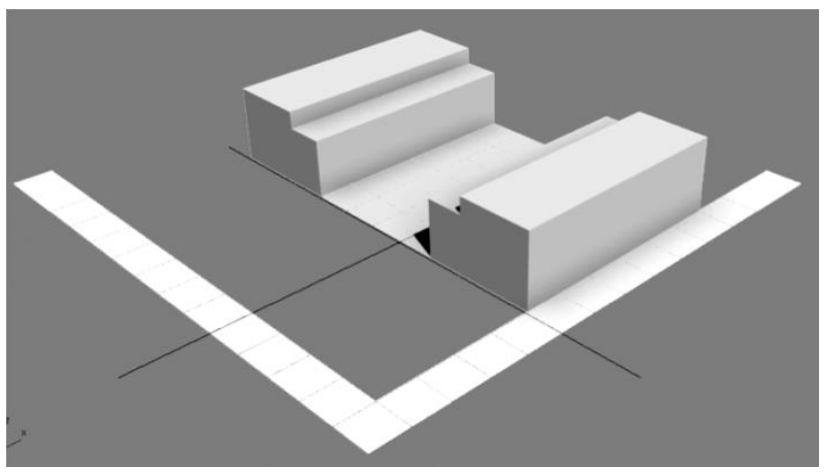

Figure 3. Middle lot layout.

Gradual constructive densification to form several courtyards according to the dimensions of the lot, but keeping an open backyard, which together with those who were adjoining, formed the so called "apple cores".

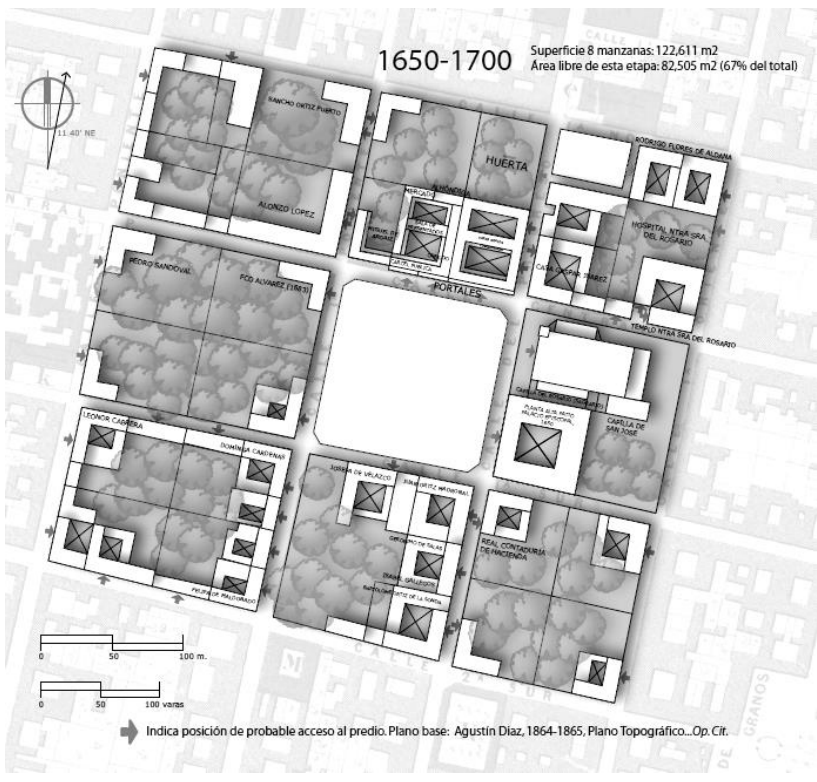

Figure 4. The "apple cores" in the middle of each block.

Other evidence is: wall thickness (the thicker, the older), different housing roof systems, volumetric arrangement (the plainer, the older), finishes, features and window openings, among others.
About specific architectural elements, a catalog of typical elements such as Tuscan columns, arches, masonry walls, windows with wood balusters, etc. was integrated. These pieces also evolved within the historical period studied.

Thereby, when referring to the "macro" and "micro" behavior of these contextual elements, then it is defined a set of criteria for "automatic modeling" that would allow the creation of valid parts for the model to complete the reconstruction of the site.

\section{WORKFLOW}

As in all parametric design, a family of initial settings and programmed relationships between them are defined. Its aim is to generate new geometry from these elements and variability restrictions allowed by such initial parameters.

The limitations of the initial parameters were dictated not by complex mathematical-geometric algorithms, but by the historical-typological features of the constructive elements.

Context was modeled with a reference workflow integrating out the following elements:

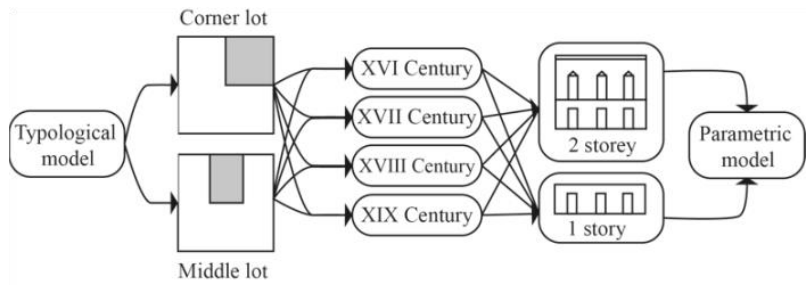

Figure 5. Workflow to determine a parametric model from typological features.

\section{PROCEDURE}

For three-dimensional modeling of the required parts RailClone (Demo Mode) plugin from Itoo Software Company applied to Autodesk's 3D Studio MAX (which integrated all parts of the models) was used. We began by defining basic units and then applied to spatial organization schemes depending on the original location of the property, its dimensions and its various historical stages.

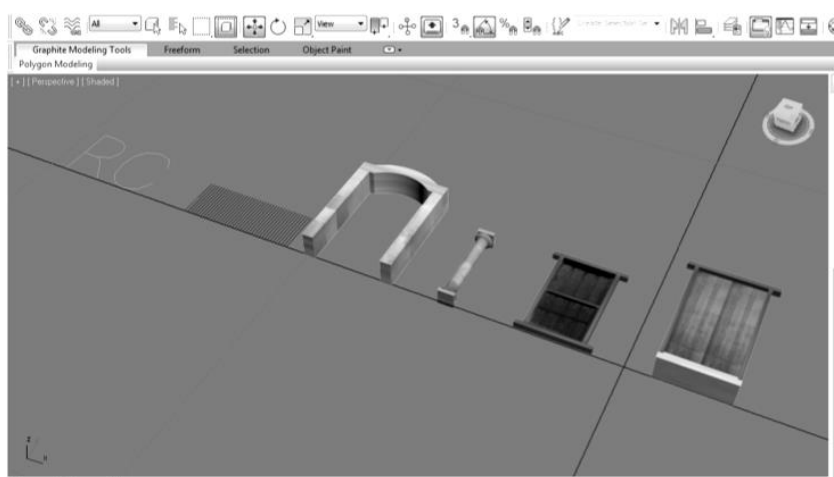

Figure 6. Colonial elements displayed as RailClone components. 


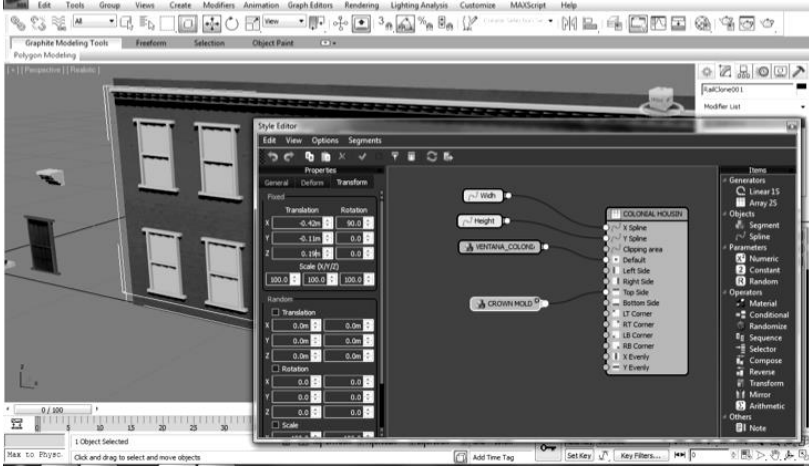

Figure 7. The "colonial-two-story-style" applied to a given wall.

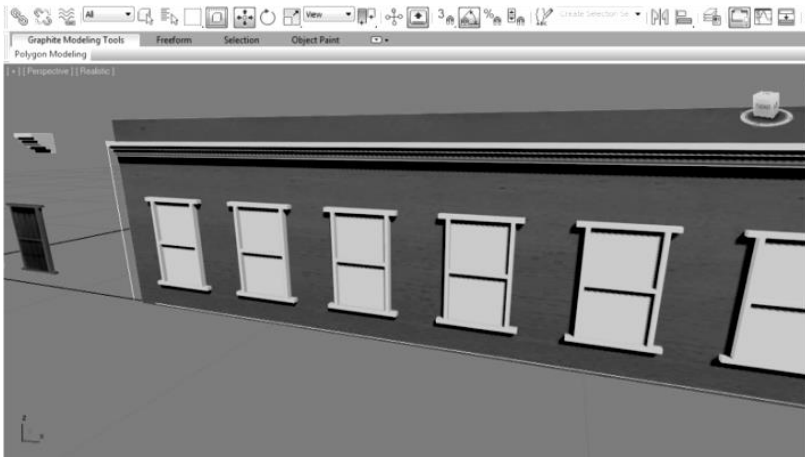

Figure 8. The same style applied on a one-story-colonial-facade.

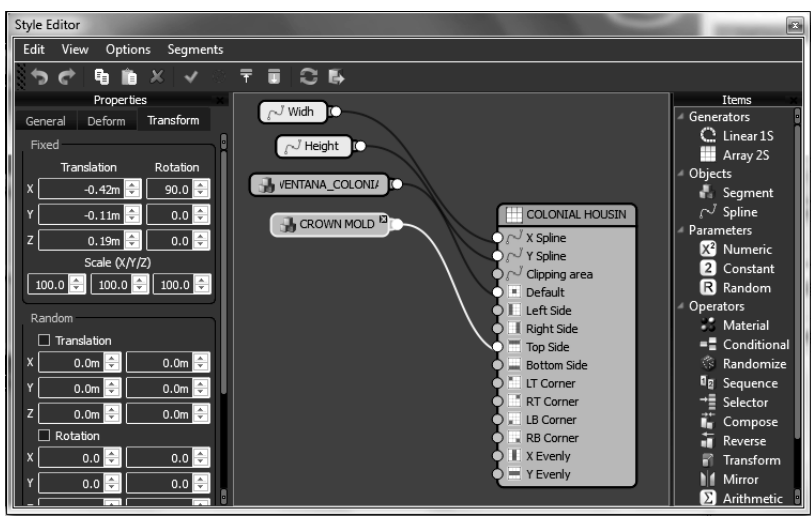

Figure 9. Detail of the applied style.

The window style parameters were: length, width, window and crown molding. These were adjusted taking into account the typical historic architectural features, such as the height of the second floor, usually larger than first floor.

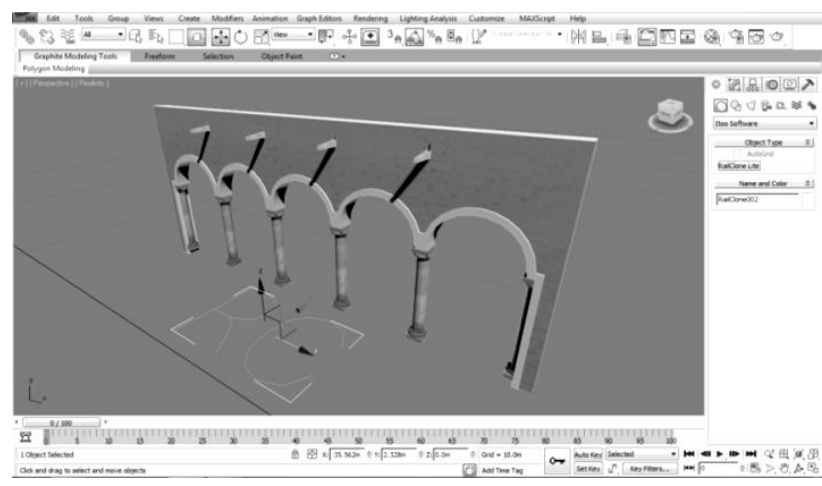

Figure 10. Archway component, gargoyles included.

In the case of the arcades of the inner courtyards, a core component of five openings with lateral rabbets was determined. It was replicated along a single line, adjusting only the padding on the corners, trying to finish in a rabbet.

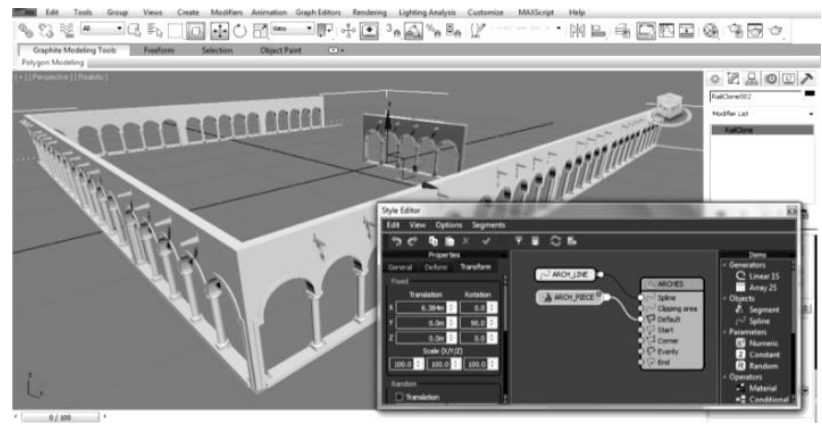

Figure 11. Detail and application of arcade style, based on Linear Array. This one had only two parameters: length and active component.

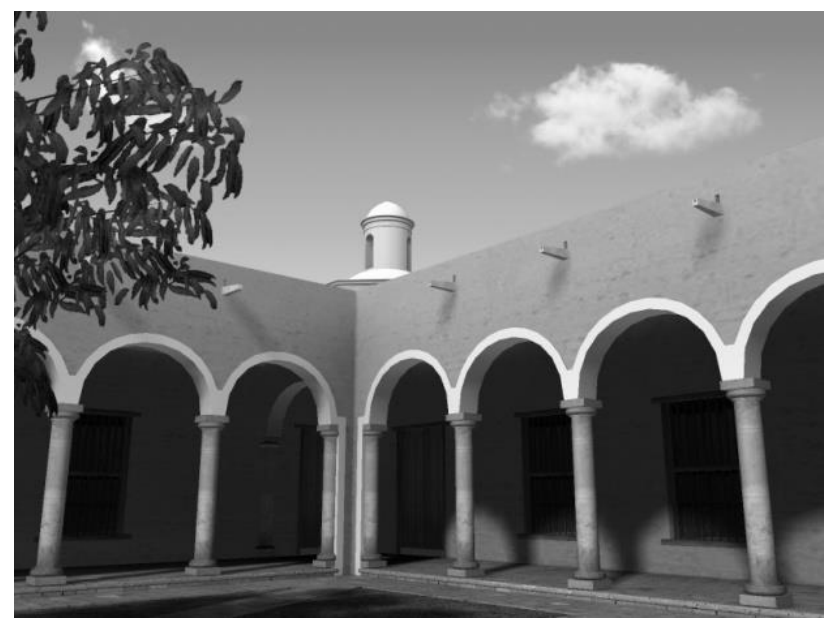

Figure 12. Application example of the styles "window" and "arcade" to specific cases.

\section{CONCLUSION}

The methodology allowed speed and accuracy in the modeling of large urban areas, since confronting models with older images we observed a certain matching between them, notwithstanding these urban images correspond to later times to the studied period.

In this way the typological - parametric modeling allows to "deconstruct" retrospectively with some degree of certainty large 
urban areas, assessing this in relation to the historical characteristics that have been properly fed into computer models.

\section{REFERENCES}

Guerrero, L. 1998. Componentes de la tipología arquitectónica, In Manuel Rodríguez (ed.), "Estudios de tipología arquitectónica”, México: UAM-Xochimilco.

Pacheco, M. 1997. Estudio tipológico de la vivienda colonial de Mérida (Mstr. Sc. Thesis), México: Universidad Autónoma de Yucatán.

Rodriguez, A. 2012. La reconstrucción histórica virtual de la Plaza Mayor de Mérida, Yucatán. Siglos XVI-XIX. Una aproximación al patrimonio cultural urbano arquitectónico por medio de las herramientas de computación visual (Ph.D. Thesis), México: Universidad Nacional Autónoma de México.

Seville Charter <consulted November 2011>, available on Internet: 〈http://www.arqueologiavirtual.com/cartaesp.php>. 